Research Article

\title{
Innovative Approaches to Cheating: An Exploration of Examination Cheating Techniques among Tertiary Students
}

\author{
Douglas Attoh Odongo (iD, Eric Agyemang $\left(\mathbb{D}\right.$, and John Boulard Forkuor ${ }^{(i D}$ \\ Department of Sociology and Social Work, Faculty of Social Sciences, \\ Kwame Nkrumah University of Science and Technology (KNUST), Kumasi, Ghana
}

Correspondence should be addressed to Eric Agyemang; ekjagyemang@gmail.com

Received 5 October 2020; Revised 2 February 2021; Accepted 5 March 2021; Published 13 March 2021

Academic Editor: Yi-Shun Wang

Copyright $(92021$ Douglas Attoh Odongo et al. This is an open access article distributed under the Creative Commons Attribution License, which permits unrestricted use, distribution, and reproduction in any medium, provided the original work is properly cited.

\begin{abstract}
The prevalence and surge in academic cheating indicate that students are finding innovative techniques to cheat during examinations. This problem has left invigilators and academic stakeholders wondering how students manage to cheat during exams. With a qualitative approach, this study sought to explore the techniques used by students during examinations. Data were gathered from students of Kwame Nkrumah University of Science and Technology. The findings revealed that the innovative techniques used by students were sitting arrangements, use of body parts, entry of foreign materials, and the use of technology. Students devised these techniques due to their perception of cheating and also poor institutional mechanism, which provided a favourable ground for cheating. We, therefore, argue that, to curtail academic cheating, not only should educational authorities and academic stakeholders improve institutional mechanism to prevent cheating, as it is the case, but also, a conscious effort should be made to alter student's perception of cheating.
\end{abstract}

\section{Introduction}

Examinations in schools, particularly at the tertiary level, have been deemed necessary for assessing students' performance in terms of their understanding of course content and its application [1]. However, in the process of performance assessment, cheating becomes inevitable [2, 3]; [4]. Cheating has become prevalent in most tertiary institutions [2]. This problem downplays the goal of assessing the understanding and application of taught courses to students $[2,3]$. Hence, the real understanding and level of knowledge of the student cannot be objectively assessed. Generally, academic cheating has both individual and institutional repercussions. To the individual, cheating dents the integrity of the individual, making him/her unworthy of trust $[2,5]$. This may lead to the suspension or expulsion of the culprit, with a negative tag on his or her academic career. This negative tag consequently prevents the withdrawn student from ever making a credible stance in the academic arena or from taking any position that requires academic recommendation $[2,5]$. Moreover, studies have proven that students who cheat their way through examinations are likely to perform poorly, leading to low productivity [6]. It has further been revealed that students who cheat, especially, during examinations, are likely to cheat as employees [6]. Hence, cheating in examinations affects prospective workers and the performance of their institution as a whole $[2,5]$. At the institutional level, cheating affects the reputation of the educational institution and its credibility; when students are issued certificates, they cannot perform practically on the job to meet their certificates. As such, this situation affects the image of subsequent students who may graduate from such institutions [7].

There are a lot of reasons why students engage in academic cheating [8-11]. Numerous studies have indicated that, from high school to graduate school, students believe that without cheating it is difficult to pass an exam $[4,12-16]$. This reason coupled with other reasons such as peer pressure, concern about grades, and student's stress has resulted in the prevalence of academic cheating in recent 
times [17-19]. This prevalence, particularly at the tertiary level, has been well documented in the literature. For instance, a study by Open Education Database [20] revealed that 68 percent of college students disclosed they have engaged in academic cheating, with undergraduate freshmen students being the most likely to engage in the act. Also, in another study by Centre of Academic Integrity [21], it was estimated that 40 percent of college students have cheated at some point in time. More alarming was a series of surveys conducted in tertiary education by McCabe et al. [22]. It was uncovered that up to two-thirds and even greater proportions of students reported some sort of cheating during their last academic year [9]. Additionally, McCabe and Bowers [23] carried out a study on undergraduate nursing and health sciences students and unraveled that, out of the 87 respondents, 87 percent acknowledged that they have cheated one way or the other. Further, a study was undertaken by Szabo and Underwood [16] on the attitude and belief of students and discovered that 50 percent of 291 students confessed to cheating. A rigorous large-scale study was conducted by Marsden et al. [24] in Australia involving 4 universities and 12 different departments. It was also uncovered that 41 percent of their sample admitted to cheating in examination [24]. All these studies reinforce the argument on the prevalence of academic cheating at the higher level.

To curtail cheating, educational institutions over the years have put in place measures to curb the prevalence of cheating $[13,17]$. Measures such as strict invigilation and the use of video cameras have all been instituted. Despite these measures, there has been a surge in academic cheating in recent times [9]. This is evident in a study undertaken by [25] that, in 1998, 49 percent of undergraduate marketing students cheated in exams as against 100 percent of undergraduate marketing students in 2008. Further, McCabe et al. [18] collected data over a decade and unraveled that academic dishonesty is widespread and there is a significant increase in academic dishonesty over a period of 30 years. This prevalence and surge have increased the growing concerns about academic misconduct $[7,18]$. Particularly, of great concern to educational authorities is an understanding of the techniques used by students to cheat during examinations. Thus, this study aims to investigate the techniques employed by tertiary students at Kwame Nkrumah University of Science and Technology.

\section{Research Methods}

2.1. Study Area. The study was carried out in Kwame Nkrumah University of Science and Technology (KNUST), in the Ashanti region of Ghana. The University has a record of 41,394 students of where 35,588 are undergraduates and 5806 are postgraduates [26]. The university is made up of six colleges. These are College of Agriculture and natural resources, College of Health Sciences, College of Humanities and Social Sciences, College of Art and Built Environment, College of Engineering, and College of Sciences. These colleges are divided into faculties, which are also further divided into departments [27].
2.2. Research Design. The research design adopted for this study was a qualitative case study. This design was used considering the fact that it provided a rich description of respondent's opinions and experiences with regard to the cheating techniques they employed during examination. Also, this research design allowed students to give a holistic account of the techniques they employed. As such, researchers were able to fully capture and make meanings out of these responses.

2.3. Study Population and Sampling Techniques. This study was part of a larger research. Data were collected from students, more precisely, undergraduate Ghanaian students. These respondents were purposively selected since they had at the time completed their final exams and submitted their long essays. Hence, they were more comfortable and open to discuss cheating with researchers. Moreover, considering the fact that final years students have gone through the entire educational system, it was prudent to use this group of students, since they have had experience with cheating throughout their stay in school. In all, a total of twenty-two (22) undergraduate students from the Kwame Nkrumah University of Science and Technology were interviewed. Twelve (12) out of the twenty-two (22) students interviewed were males while the remaining ten (10) were females. Out of the twenty-two (22) students, four (4) were offering programs in College of Humanities and Social Sciences, three (3) students came from the College of Architecture and Built Environment, four (4) students were also selected from College of Science, another four (4) students were interviewed each from the College of Agriculture and Natural Resources and the College of Engineering, and finally three (3) students were selected from College of Health Sciences. The essence of selecting students across colleges was to obtain varied techniques used among students in Kwame Nkrumah University of Science and Technology (KNUST) during examinations.

2.4. Data Collection. With the aid of a semistructured interview guide, data were gathered from 22 respondents. All the interviews were recorded, carried out in English, and lasted about 25 minutes. These interviews were undertaken at different spots on campus. Although some respondents were initially hesitant since this study touched on cheating, however researchers guaranteed these respondents that the information from this study was for academic purposes and nothing else. Also, respondents were informed that they had the right to refuse to answer a particular question or withdraw completely from the entire interview if they feel so. Further, respondents were asked to give consent before the interview begun and also assured of anonymity. Respondents were assured that recorded interviews will only be accessible by the researchers to ensure their confidentiality.

2.5. Data Analysis. All interviews were audio-recorded. The analysis started with the transcription of the gathered data. These data were transcribed ad verbatim and researchers 
conducted thematic analysis on the data. The main aim of the study was to investigate the cheating techniques used by the students during an examination. As such, the transcripts were read through and re-arranged under the research question. After the organization of these transcripts, relevant codes were identified. Subsequently, similar codes were brought together to reflect the research question. For instance, codes such as writing on body parts, wearing of indecent dresses, and the usage of signs and gestures were grouped under the theme, use of body, which was presented in the results section. These themes were reviewed to ensure that they accurately reflected the meanings in the data and addressed the overall research question. The review also explored how specific themes complemented or challenged other themes in presenting a holistic understanding of the aim of the study.

\section{Results}

The results are presented based on the research question that guided the study, that is, the cheating techniques students used during examinations. In answering the research question, the themes that emerged through the analysis are presented narratively.

3.1. Use of the Body. The first theme that emerged was the use of body parts. Most respondents indicated that one's body part aided in cheating, since it serves as a convenient means of transporting answered questions and predetermined answers into the exam hall. The commonest technique used by these students was writing on body parts. This could be in their palm or hand and for most ladies who had on straight dresses and skirts, they wrote on their thighs. Writing on body parts involves personal communication with oneself and it is assumed to be the safest means of cheating.

Mmmm.... Ok... some of us write on our thighs and hands, and even under our feet. As such, we wear slippers to the exam hall. As for me, I make sure water does not touch my feet or else it will clean the pen ink, and I will lose everything. I think it is safer than other techniques. R4 (Male)

However, under intense invigilation, it appeared that some students preferred not to use the technique of writing on body parts. As such, they prefer to openly communicate with their colleague by using signs and gestures. The meaning assigned to these signs and gestures are preplanned by the students, and most suitable for answering objectives.

If we plan to cheat, we make sure we are always with our friends when entering the exam hall. We sit closer to each other, sometimes sideways so that we can ask. We use gestures such as hands and symbols. Aha, you can even blink your eye to draw a friend's attention to a mistake or a correct answer. For the objectives we use signs. A is for $1, B$ is for 2 then it follows. R4 (Male)
I think the most common technique everybody is familiar with is tapping someone during the examination or nodding, especially when the person asking is sitting behind you. So, you just nod to agree to a particular answer when asked. Other times too, you can use your fingers to communicate answers during the objective part like a single finger signifying answer ' $A$ ' or two fingers meaning answer 'B. R1 (Female)

In answering the objectives, these students use fingers to represent answers. For instance, the little finger would be used for answer "A," index finger for answer "B," middle finger for answer "C," and so on. Nonetheless, there are limitations to this kind of technique as some lecturers have now invented a way of setting alternative questions for their students. So, within the exam hall, we will have different question papers for the same batch of students.

Moreover, when it comes to answering the essay aspect of the exams, thus section "B," students need to use very minimal sound in making techniques to draw the attention of their colleagues. Making sound with the foot is one of the commonest techniques that draw the attention of a colleague nearby to engage in cheating. Students sometimes hit their foot on the ground to feign tiredness and therefore the need to exercise and massage their foot to let blood flow well through their body. Therefore, right after stamping one's foot, follows the technique of whispering and at times eavesdropping.

Sometimes, it is difficult to draw your friend's attention. So, when that happens I sludge back on the chair and stretch my legs to hit the person in front of me...or anything that would help. R3 (Male)

In fact, examination makes people who are mostly unprepared to do crazy stuff. At times, we use stones. We take small stones, like pebbles, with us into the exam hall. When one calls a friend and the friend does not heed to the call, we throw the stone at the person. [Laughs] We throw the stone to alert the person. R5 (Male)

Among the various ways students use their body parts to cheat, the most interesting and innovative technique is how sometimes the body part is used to cheat. For instance, at times, female students enter the exam hall with very tight and short clothing with the intention to reveal some sensitive parts of their bodies. Revealing of the thighs or breasts is used as a tool to make male invigilators uncomfortable so that they continuously talk with their colleagues; hence, they cheat.

If they refuse to leave then we force them to leave, especially male invigilators [laughs]... [I: How?] ...okay for the females when we sit, we just open our thighs. Some of them cannot stand it so they just go outside, then we cheat. $\mathbf{R} 2$ (Female)

I have seen it before. The female students would wear a mini skirt. . like the type of dresses that would expose themselves. Especially the breast. I do not know how they think but 
when they get to the exam hall that is where they show themselves and sometimes it favours them. R6 (Male).

3.2. Sitting Arrangement. Sitting arrangement was also mentioned by respondents as a technique that helped them cheat. For this technique to be successful, there is the need for students to arrange themselves into the right sitting positions. A popular sitting arrangement known among students is "formation." A technique that requires group dedication and conscientiousness. There are two types of "formation." The first type requires the input of all cheating students. With this type, there is division of labour, in terms of what each student is to learn for exams. The course content is divided among those who will cheat in the exam hall. Each student takes a section of the course material and learn. Afterward, students would, before entering the exam hall, come together to pre-plan where they will be sitting for effective discussion and deliberation of answers to an exam question.

There is this "formation" technique we use. For instance, when we are going to write an exam and what we are trying to study is difficult, we divide the course material among ourselves and sit around ourselves in the examination hall. So, when this person needs help with this area, the one who studied that part teaches the others. That one is not really cheating, it is teamwork. Just like football [formation?] yes! R6 (Male)

However, what limits the effectiveness of this technique is the reshuffling method adopted by most invigilators. Some invigilators wait till all students have settled down and taken their positions and they will come in to rearrange them all over again. Others will also let the students line up, make them come in one after the other, and allow them to take a seat and leave an empty seat before and after them. This method employed by invigilators to prevent cheating is effective since a lot of wider spaces are left around the student, making communication very difficult.

But nowadays, the formation technique is difficult to employ, you get into the exam hall, you sit, then the invigilators will enter and rearrange all of us again. R3 (Male).

It works when the sitting position is okay, but when the sitting position is changed, ahh then it messes everything up. Sometimes too it depends on the lecturer who would be supervising you and the classroom block within which you would be writing your paper. R2 (Female)

Unlike the first type, the second type of "formation" does not require the input of all members. The success of the second type is dependent on a brilliant student or a group hero. A group hero relays all information to those around him/her. These students measure the intelligence of the group hero by their ability to answer questions frequently in class.
We have some formula that we call 4, 4, 2 or 4, 4, 3, formation. Thus, four would sit behind, then one here and one there. We place the most brilliant one in the middle. As in the number ' 6 ' in football. He coordinates the attack and defense simultaneously. He should be someone who answers questions frequently in class and should be very good. If a lecturer changes his sitting position, that is it. We are all doomed. R7 (Male)

While some students prefer to use the "division of labour" method where they would divide the task of recalling information among themselves, others also employ the brilliant student strategy. In all, these strategies are well coordinated and well planned among those who employ them.

3.3. Foreign Material. The findings further revealed that students sneaked in already answered questions, preconceived answers, and formulas on papers into the exam hall by hiding them in their dresses, shoes, socks, hair, purses, inside calculators, and pen covers or containers. In some instances, students hid these foreign materials at places they know they would sit during an exam.

We sometimes sneak in answered questions or written answers to the exam hall. Well, most people cannot do it. I think this type of cheating is for the brave or high risktakers. People shiver when the invigilator is Infront of them because they have foreign materials on them. This type of cheating is not like the one you ask a friend. With this, there is evidence, if you are caught you will be dismissed. But the brave ones carry foreign materials on them R2 (Female).

Some students either write on a sheet of paper and then attach it to their belts or write directly on their belts. The nature of most belts does not allow invigilators to see written answers. So, these students mostly fill their belts with answers, which they have foreknowledge of and since the belt is much closer, they can easily manage to transfer the answers onto the answer sheet by fiddling or act playfully with their belts.

I attended a girls' school so we use to put on a belt as part of our uniform. In this case, we use to cut the inner part of the belt to hide pieces of paper to carry into the exam hall. $\mathbf{R 8}$ (Female)

The entry with foreign material is more effective when students are not made to go out of the hall but only told to put their books and bags away as it is done in some internal assessments such as class quizzes.

Entering with foreign material is easier with mid-semester exams, quizzes and Internal assessments. With the end of semester exams, we are already outside, searched and told to take a seat. But with other types of exams, such as the mid-semester exams, quizzes and Internal assessments we are already seated and told to put all books and bags aside. 
With this, it is easier to use the foreign material $\mathbf{R} 4$ (Female).

Another means of which most invigilators are unaware is writing answers on handkerchiefs. Due to the nature and purpose of a handkerchief, invigilators feel reluctant to inspect or prevent students from entering the exam hall with one. Most times, the handkerchief appears folded; hence, it does not occur to the invigilator to search it.

Yeah, it is true. We sometimes send a handkerchief with written answers on it to the exam hall. People can write on their handkerchiefs and open it in front of them, so if the lecturer is coming, they just fold it and wipe their face with it as if they are sweating. When the lecturer turns away, they will open it and continue. R3 (Male).

I think the handkerchief is the smartest way without being caught. R9 (Female)

3.4. Technological Devices. The advent of technological devices such as calculators, digital watches, and ultraviolet (UV) pens has aided students to cheat during examinations. Most students asserted that technology, particularly calculators, made it easier and convenient to cheat during an examination. Calculators have the ability to save and recall answers. As such, some students record answers of past questions received from reliable sources onto the calculator, to use during exams. This form of cheating is presumed to be the easiest and safest form of cheating and practiced among statistics, engineering, and any other students offering mathrelated courses. These students call this technique of cheating-being smart.

I remember when my friend told me about how a calculator can be used to save answers and used during examinations. I was excited about it. We saved objective questions on it and used them during exams. With this technique, you need to be sure that whatever you are saving on the calculator will come in the exam. There are instances we stored answers and when we go to the exam hall it is a different question R4 (Male).

Other students have complex watches that can record and keep information. Some of these watches, mostly digital watches, look a lot like a calculator. These watches were used to save answers just like the calculator.

I had this digital watch which looked like a calculator....I normally stored objectives on it. Before I get into the exam hall, I made sure the battery was fully charged and every answer has been properly stored well. I do not want any surprises. R3 (Male)

In addition to calculator and watches, UV pen was also mentioned as another technology used by students to cheat during exams. In using UV pens, these students write the answers with an empty or inkless pen on any material they are permitted to take into the exam hall. In the course of the exam, all they did was to shine or focus the red rays of the pen onto the surface; then, all the answers would appear.

Most invigilators are aware of other technological devices that students use to cheat but with the UV light, most of them are not aware. They think it is an ordinary pen. Well, I sometimes tell some of the invigilators that is an ordinary pen. I have an inkless pen, that comes with the UV pen. All I have to do is write all perceived answers on a sheet in my mathematical set and send it in. Thereafter, I use the UV light to reveal the answers. Easy right?? R9 (Male)

Also, in certain instances, students take the risk and enter the exam hall with phones. They take pictures of questions and WhatsApp these questions to friends outside the exam hall. Their friends will cross-check the questions with the course content and send the answers back to those in the exam hall.

I have witness one before, there was this paper that we were writing, eh was it HR, yes it was HR. This guy was using a phone in the exam hall. Real phone in the exam hall. I could not believe it. I was sitting right behind him and he was taking pictures of the questions. I presume he was sending it to his friends outside who will send him the answers back. He was somewhat distracting me, I must admit. Throughout the paper, all that I was thinking was, what if he is caught? R9 (Male)

The effectiveness of the use of technology in cheating during exams is based on how well these students predicted answers to examination questions.

\section{Discussion}

This study has revealed the various cheating techniques tertiary students used during examination. These techniques are the use of body parts, sitting arrangements of students, entry of foreign materials, and the use of technology. Students, as rational beings, devised these innovative techniques to enable them to cheat during an examination. For instance, the technique of using body parts, which was also uncovered by Shon [28] in her study, is a classic example of how students are driven to pass at all costs. Just like Shon's [28] study, this study unraveled that students wrote on their palms and thighs and even made sounds or gestures with their hands and feet. The innovativeness of this technique was the exposure of body parts by female students to either distract or make invigilators uncomfortable. The use of the body in this manner illustrates the length at which students will go to accomplish their goals. Also, reflective of how innovative these students are, is how they sat to communicate. To students, this sitting arrangement is known as "formation." The concept of "formation" is mostly used in association football where football players are tactfully positioned on the pitch. Coaches arrange players on the pitch in a strategic manner to win against their opponents. These students implement the same technique in such a way that they have strikers (the smart ones), mid-fielders (the 
mischievous ones to pass answers around), and defenders (those to give heads up to the team when an invigilator is coming) - with the aim of obtaining a win (cheat) in the exams. Although this sitting arrangement can be found in the literature, its execution is unique and innovative. Additionally, this study unraveled how foreign materials were introduced into the exam hall by students. The finding from this study is consistent with that of Madara and Namango [29]. Regarding this technique, as Choi [17] indicated, the drive to cheat is necessary but not sufficient to execute this technique. The absence of an invigilator, in addition to the drive to cheat, makes this technique effective. A combination of these conditions helped students succeed with this technique. Finally, the use of technology was unraveled as another technique students used to cheat. This technique was also revealed in a study conducted by [9]. Due to the nature of some of these technologies, students normally get away with such technique, since most of these technologies are hard to detect.

In discussing why students devised techniques to cheat, some researchers have argued that sanctions for the violation of every codes and conducts have been explicitly stated by every educational institution, so if students go out their way to cheat, these sanctions should be meted out on them $[13,30,31]$. These researchers further argued that students have a moral obligation not to cheat, yet, their actions are directly opposite to what is expected of them $[12,13,30,31]$. They go to great lengths to indulge in the act irrespective of the consequences [13], from writing on their thighs to learning how to sit in a formation manner to cheat. This insistence on their part, according to Elias [12], is due to the perception of cheating among students. It has been well established that the perception of students with regard to cheating has a positive correlation to their indulgence in the act $[8,10,11]$. Gomez [32] indicated that cheating is perceived by most students as a victimless crime, which has no direct implication on them or the institution, an act to help them pass an exam, thus, demonstrating the no-bigdeal phenomenon [32]. Such perception of cheating, irrespective of the consequences, explains not only the prevalence of cheating but also why they devise techniques to cheat. Alternatively, other researchers have tried to shift the attention from students to poor institutional mechanisms [33-35]. These researchers argued that students can be driven by their perception and other factors to cheat, but when institutional mechanisms are effective, cheating can be curbed $[34,36]$. One important aspect of institutional mechanism that provides favorable conditions for cheating is poor invigilation during examination [33]. It has been well established that one major cause of cheating is poor invigilation [3, 34, 37]. Poor invigilation ranges from lectures sleeping in class during an examination to the marking of scripts whiles invigilating [38]. For instance, the study by Nyamwange et al. [39] pointed out that some invigilators slept while exams were ongoing. This provided a fertile ground for cheating, as students took advantage of the situation to execute their techniques to cheat [39]. Apart from sleeping, others are known to mark scripts or read scripts during an examination. A study by Njeru [14] uncovered that, instead of lectures to invigilate during exams, they spent their time marking papers and reading scripts. This also provided a favourable condition for students to put in place the various techniques for cheating [14]. Also, some lectures are known to ignore or fail to report students who indulge in the act. McCabe et al. [18] in their study indicated that some students were of the view that sometimes lecturers ignore them when they are caught cheating. A poor system presents an opportunity for students to execute these techniques to cheat.

We acknowledge the fact that the perception of students with regard to cheating has everything to do with why they cheat (reasons) and how they cheat (techniques). However, we are not disputing the fact that a poor institutional mechanism provides a favourable condition for students to devise techniques to aid them to cheat during exams. We, therefore, argue that both the perception of students and the institutional mechanism go a long way to determine whether students will devise techniques or not. As such, in tackling cheating in school, especially at the tertiary level, we advocate that not only should university authorities pay attention to the institution mechanisms, as it is the case, but also measures should be put in place to change the perception of students regarding cheating. In other words, students should be sensitized on what constitutes cheating and the implications of cheating on students and the institution as a whole.

\section{Conclusion}

Throughout this study, the various techniques for cheating in an examination have been emphasized. Academic cheating occurs, when students write on parts of their body, when students enter with foreign materials, when students use technology to cheat, and when they sit in a manner to communicate during an examination. Since cheating is a problem in every educational institution, these techniques are widely adopted by most students. In explaining why students develop techniques to cheat, this study has clearly indicated that students are rational beings and are influenced by their perception and a poor institutional mechanism. We, therefore, argued that, to curtail academic cheating, educational authorities should not only improve institutional mechanism to prevent cheating (as it is the case) but also make a conscious effort to alter students' perception on cheating.

\section{Data Availability}

The data that support the findings of this study are available on request from the corresponding author, Mr. Eric Agyemang.

\section{Conflicts of Interest}

The authors declare that they have no conflicts of interest. 


\section{References}

[1] R. Balfanz and V. Byrnes, "The importance of being in school: a report on absenteeism in the nation's public schools," The Education Digest, vol. 78, no. 2, p. 4, 2012.

[2] A. Diego, "Friends with benefits: causes and effects of learners' cheating practices during examination," IAFOR Journal of Education, vol. 5, no. 2, pp. 121-138, 2017.

[3] J. B. Forkuor, J. Amarteifio, D. O. Attoh et al., "Students' perception of cheating and the best time to cheat during examinations," The Urban Review, vol. 51, no. 3, pp. 424-443, 2019.

[4] F. Mutala, Factors influencing sustainable solid waste management: a case of Thika Town, Ph.D. thesis, Doctoral dissertation, University of Nairobi, Nairobi, Kenya, 2016.

[5] L. L. Attoh, F. Gino, and M. H. Bazerman, "Dishonest deed, clear conscience: when cheating leads to moral disengagement and motivated forgetting," Personality and Social Psychology Bulletin, vol. 37, no. 3, pp. 330-349, 2011.

[6] M. I. Syam, "The factors that lead to cheating in exams and how to avoid them," GSTF Journal on Education (JEd), vol. 1, no. 2, 2014.

[7] P. B. Dusu, A. Gotan, J. Mohammed Deshi, and B. Gambo, "Management of re-occurring cases of examination malpractice in plateau state college of health technology Pankshin, Nigeria," Journal of Education and Practice, vol. 7, no. 6, pp. 38-43, 2016.

[8] L. Cifuentes and A. Janney, "Protecting students' integrity and reducing academic dishonesty in online learning," Distance Learning, vol. 13, no. 4, p. 9, 2016.

[9] D. L. McCabe, K. D. Butterfield, and L. K. Treviño, “Academic dishonesty in graduate business programs: prevalence, causes, and proposed action," Academy of Management Learning \& Education, vol. 5, no. 3, pp. 294-305, 2006.

[10] J. Robinson and G. Perry, "Building a culture of academic integrity: what students perceive and need," College Student Journal, vol. 51, no. 2, pp. 209-221, 2017.

[11] R. Elias and M. Farag, "The relationship between accounting students' love of money and their ethical perception," Managerial Auditing Journal, vol. 25, no. 3, pp. 269-281, 2010.

[12] R. Elias, "The effect of machiavellianism on business students'perception of cheating," Academy of Educational Leadership Journal, vol. 19, no. 1, p. 175, 2015.

[13] D. McCabe, "Cheating and honor: lessons from a long-term research project," Handbook of Academic Integrity, Springer, Berlin, Germany, pp. 187-198, 2016.

[14] I. Njeru, "Causes, frequencies and trend of student cheating in school examinations," Unpublished Research Project, Kenyatta University, Nairobi, Kenya, 2008.

[15] T. H. Stone, I. M. Jawahar, and J. L. Kisamore, "Predicting academic misconduct intentions and behavior using the theory of planned behavior and personality," Basic and Applied Social Psychology, vol. 32, no. 1, pp. 35-45, 2010.

[16] A. Szabo and J. Underwood, "Cybercheats," Active Learning in Higher Education, vol. 5, no. 2, pp. 180-199, 2004.

[17] C. Choi, "The pull of integrity," ASEE Prism, vol. 18, no. 7, p. 29, 2009.

[18] D. L. McCabe, L. K. Trevino, and K. D. Butterfield, "Cheating in academic institutions: a decade of research," Ethics \& Behavior, vol. 11, no. 3, pp. 219-232, 2001.

[19] B. Rosamond, "Plagiarism, academic norms and the governance of the profession," Politics, vol. 22, no. 3, pp. 167-174, 2002.

[20] Open Education Database, 8 Astonishing Stats on Academic Cheating, OEDB, Houston, TX, USA, 2010, http://oedb.org/ ilibrarian/8-astonishing-statson-academic-cheating/.
[21] Centre for Academic Integrity, "Related research," 2010, http://www.academicintegrity.org/cai_research/cai_related_ resrch.php.

[22] D. McCabe, K. D. Butterfield, and L. K. Trevino, Cheating in College: Why Students Do it and what Educators Can Do about it, JHU Press, Baltimore, MD, USA, 2006.

[23] D. McCabe and W. Bowers, "The relationship between student cheating and college fraternity or sorority membership," NASPA Journal, vol. 46, no. 4, pp. 573-586, 2009.

[24] H. Marsden, M. Carroll, and J. T. Neill, "Who cheats at university? A self-report study of dishonest academic behaviours in a sample of Australian university students," Australian Journal of Psychology, vol. 57, no. 1, pp. 1-10, 2005.

[25] B. Brown, R. Weible, and O. Kurt, "Business school deans on student academic dishonesty: a survey," College Student Journal, vol. 44, no. 2, pp. 299-309, 2010.

[26] Kwame Nkrumah University of Science and Technology, 51st Congregation Programme, 4th to 8th July 2017, University Printing Press, Kumasi, Ghana, 2017.

[27] Kwame Nkrumah University of Science and Technology, Student's Guide, University Printing Press, Kumasi, Ghana, 2016.

[28] P. Shon, How College Students Cheat on In-Class Examinations: Creativity, Strain, and Techniques of Innovation, MPublishing, University of Michigan Library, Ann Arbor, MI, USA, 2006.

[29] D. S. Madara and S. S. Namango, "Faculty perceptions on cheating in exams in undergraduate engineering," Journal of Education and Practice, vol. 7, no. 30, pp. 70-86, 2016.

[30] T. B. Gallant, N. Binkin, and M. Donohue, "Students at risk for being reported for cheating," Journal of Academic Ethics, vol. 13, no. 3, pp. 217-228, 2015.

[31] B. Meiseberg, T. Ehrmann, and A. Prinz, "“Anything worth winning is worth cheating for"? Determinants of cheating behavior among business and theology students," Journal of Business Economics, vol. 87, no. 8, pp. 985-1016, 2017.

[32] D. S. Gomez, "Putting the shame back in student cheating," The Education Digest, vol. 67, no. 4, p. 15, 2001.

[33] X. Li and Y. Meng, "How to prevent college students from cheating in exams? based on game theory," International Journal of Research Studies in Science, Engineering and Technology, vol. 3, no. 9, pp. 39-42, 2016.

[34] J. A. Ogunji, "Examination management and examination malpractice: the nexus," Journal of International Education Research (JIER), vol. 7, no. 4, pp. 53-64, 2011.

[35] E. Taderera, L. Nyikahadzoi, M. Wilson, and E. Mandimika, "Exploring management strategies to reduce cheating in written examinations: case study of midlands state university," Journal of Case Studies in Education, vol. 5, 2014.

[36] R. James, "Tertiary student attitudes to invigilated, online summative examinations," International Journal of Educational Technology in Higher Education, vol. 13, no. 1, p. 19, 2016.

[37] S. A. Shariffuddin and R. J. Holmes, "Cheating in examinations: a study of academic dishonesty in a Malaysian college," Asian Journal of University Education, vol. 5, no. 2, pp. 99124, 2009.

[38] A. C. Ifeakor and J. U. Anekwe, "Achieving standard in secondary education through the eradication of examination malpractices: the Nigerian experience," African Research Review, vol. 4, no. 4, 2010.

[39] C. Nyamwange, O. Paul, and O. Peter, "Factors influencing examination cheating among secondary school students: a case of Masaba south district of Kisii county, Kenya," Elixir Psychology, vol. 56, pp. 13519-13524, 2013. 